\title{
Estética e política, memória e esquecimento: novos desafios na era do Mal de Arquivo
}

Márcio Seligmann-Silva

\section{O teológico-político e o estético-político}

Nossa era de terrorismos e fundamentalismos, baseada em um pensamento cada vez mais (novamente, sempre...) religioso, faz com que nos perguntemos se o famoso constructo de Carl Schmitt, o teológico-político, não teria triunfado na nossa cultura política. Ou seja, a derrota do nazi-fascismo foi aparente quando levamos em conta essa continuidade dos padrões teológico-políticos de nossa era. Mas não se trata apenas de um triunfo da "infame", para lembrarmos da expressão carinhosa que Voltaire reservou à igreja. Também notamos hoje uma continuidade da matriz estético-política. Walter Benjamin, como é bem conhecido, fechou seu texto sobre a obra de arte na era da sua reprodutibilidade técnica diagnosticando o nazismo como uma "estetização da política" (BENJAMIN, 1989, p. 384). Essa interpenetração do estético e do político é, na verdade, bem mais profunda do que Benjamin imaginou. Existe uma profunda relação entre a história da arte e de sua reflexão e, por outro lado, a história do pensamento e das práticas políticas. O nazismo teria sido apenas o auge desta longa história. O campo das artes sempre serviu como dispositivo de reflexão e aprimoramento de dispositivos de identificação. As artes atuam no campo das formas, das proto-formas, poderíamos escrever platonicamente. Nelas, moldes identitários sempre foram e continuam a ser produzidos. Se o homem atua no mundo a partir de sua constante leitura e interpretação do mesmo, esse processo de leitura é guiado por uma gramática das formas que é em grande parte gerada pelas artes. Elas produzem a ontotipologia, os tipos que estão na base de nossos julgamentos não apenas estéticos, já que essa mesma ontotipologia impregna nossos juízos éticos e políticos também. Na nossa era do politicamente correto isso está mais claro do que nunca. A atual racialização do político é apenas mais um triunfo dessa força ontotipológica. O fato de ela se dar muitas vezes em meio a boas intenções (a justificada defesa das minorias subalternas) pouco importa: a ontotipologia, o estabelecimento de tipos e formas pensados como identidades autônomas e fechadas, é o suficiente para se instaurar um modo de pensar fascista, ou seja, um modo de pensar antes de mais nada inimigo do "outro", incapaz de perceber a identidade como jogo de diferenciação, como falta e não como condição ôntica e fechada do ser.

É verdade, por outro lado, que nem toda arte serve de modo subserviente a essa máquina de formas e de tipos. Muitas obras justamente trabalham no sentido de desconstruir esse jogo ontotipológico. Elas tentam sabotar nossos hábitos de julgar e de repetir identificações de modo mecânico. Assim podemos ler as obras de artistas, filósofos e escritores como Baudelaire, Duchamp, Kafka, Benjamin, Francis Bacon, Derrida ou Beckett. Neles vislumbramos o Eu como jogo de máscaras, como impossibilidade de identidade. Por outro lado, como justamente nossa época tem esse veio fundamentalista, 
expressões estéticas facilmente estão na origem de novas querelas estético-políticas. Esse foi o caso recente, em 2006, das publicações de caricaturas de Maomé (apresentado como terrorista) do diário dinamarquês Jyllands-Posten (e que foram republicadas em outros diários, como o France-Soir, o La Stampa italiano, o alemão Die Welt e o espanhol El Periodico). Não por acaso essa querela surgiu justamente da caricatura, a arte de desfigurar comicamente, ironicamente e de modo crítico, as faces, a base da nossa percepção das identidades. A ontotipologia tem o nosso rosto como a sua pedra de toque. O political statement das caricaturas do Jyllands-Posten estava claro. A questão é que, na nossa era do politicamente correto, publicar caricaturas como essas significa uma declaração de guerra. Nas democracias, os políticos podiam ser caricaturados, mas, na nossa guerra ontotipológica, uma caricatura dessas tem o valor de um míssil. Como tendemos a pensar o político a partir de identidades étnicas e de preceitos religiosos, não existe espaço para a ironia, muito menos para a caricatura. O humor fica banido e no lugar dele vemos surgirem novas modalidades do Index Librorum Probibitorum.

Todos somos também mais e mais obrigados a confessar nossas raças, ideologias e religiões - senão em tribunais, ao menos em formulários oficiais. As políticas são feitas em torno dessas etiquetas. A biopolítica leva de roldão categorias e práticas da política - elas também problemáticas, mas ao menos não tão fascistas quanto as do biopolítico. O culto de imagens e espaços simbólicos que representem a unidade da comunidade política corresponde a uma sociedade que pensa por categorias estanques. Se na era moderna as nações erigiam grandes monumentos e comemoravam a pátria em torno deles, agora as sociedades articulam suas memórias em arquivos que são utilizados como argumentos na guerra de identidades. Ao invés de opormos de modo crítico ao registro positivista da historiografia novas práticas, mais abertas, em diálogo com a memória, que permitem incorporar a história oral, as imagens, a relação da memória com seus locais, as novas modalidades de memória estão sendo canalizadas para discursos ainda mais rígidos e cegos à outridade do que o patriotismo que sustentava a historiografia até há pouco. Os monumentos e toda uma imagerie da comunidade política são utilizados na criação de uma nova concepção do próprio, seja esse pensado como etnia, raça, nação ou pátria. Os dispositivos de memória ajudam a desenhar a face do próprio. Devemos entender nesse sentido o papel das obras de arte como auxiliares desse design do rosto da comunidade. Um exemplo dessas querelas da identidade/memória aconteceu na Estônia, em torno do monumento aos soldados russos da Segunda Guerra ("Soldado de Bronze") em Tallinn. Esse monumento foi retirado do seu local de destaque. $\mathrm{Na}$ ocasião, Mikhail Kaminin, porta-voz da diplomacia russa, declarou: "O Monumento ao Combatente Libertador foi desmontado em vésperas de uma festa sagrada: o Dia da Vitória [sobre a Alemanha nazista em 1945]. E isso só se pode classificar de sacrilégio e desumano" ("Rússia estuda sanções contra Estónia”). O sagrado e o político estão lado a lado: uma obra de arte monumental, que representa também um marco da dominação soviética, é lida como um documento religioso e índice de humanidade. Nossos conflitos políticos tornam-se de modo explícito querelas em torno da memória. Territórios e populações, para afirmar sua identidade, cultuam mais e mais imagens que lhes garantem uma força de identificação mimética. Trata-se de um modo arcaico e violento de identificação, que Adorno e Horkheimer descreveram como estando na base do processo de hominização e que teria 
como origem o medo do Outro. ${ }^{1}$ Nosso desafio é aprender a lidar com a nossa cultura da memória sem reproduzir essa tendência à mímesis mecânica que responde à necessidade primitiva de proteção e autoconservação. Como escreveu Vilém Flusser (2007), devemos aprender a viver novamente no nomadismo, na Heimatlosigkeit (a apatricidade), por mais duro que possa ser este aprendizado.

\section{Arquivos}

Falar hoje de arquivos, de colecionismo, de listagens e de musealização tornou-se quase uma obsessão. Faz parte de nossos atuais rituais acadêmicos recordar essa nossa cultura da memória. É imperativo hoje descrever e tentar entender essa nossa nova paisagem arquival. É como se de repente todos nós tivéssemos ficado conscientes de que cultura é memória: uma asserção que já era verdade para pensadores como Aby Warburg, Walter Benjamin, Maurice Halbwachs, Freud, entre tantos outros. Mas é claro que falar que cultura é memória não é o mesmo que falar que cultura é arquivo, ou ainda, que cultura é musealização. Esses termos devem ser bem pesados e avaliados dentro de cada época e autor que os emprega. Podemos pensar também que essa "virada memorialista" não é de agora e pode ser retraçada como mais uma etapa em uma antiquíssima reflexão sobre a escritura e a nossa relação com os dispositivos de inscrição. Da cultura egípcia, de Platão e Aristóteles até Foucault e Derrida, acompanhamos uma longa história de reflexão sobre a memória, o arquivo e a escritura. Muito já se publicou sobre esse tema nas últimas décadas. Nesta história, por outro lado, é verdade que vivemos um capítulo ímpar, marcado pelas profundas mudanças tecnológicas e pela paralela revolução em nossa visão do homem e da cultura.

A nossa atual "virada memorialista" é sem dúvida um dos momentos de maior destaque dentro de um outro movimento que convencionamos chamar de "virada culturalista". O culturalismo representa a um só tempo o esgotamento e a tentativa de superação dos grandes modelos explicativos, teleológicos e ainda comprometidos com o Iluminismo do século XVIII. O modelo iluminista foi profundamente abalado não apenas pelas experiências históricas das guerras e pela "banalização" dos genocídios, mas também pelas inovações trazidas pela psicanálise e pelas vanguardas, e também, e acima de tudo na última década, pela entronização do saber biológico. As chamadas ciências humanas, que lutaram durante os séculos XIX e XX para se verem independentes do modelo de saber científicos das ditas ciências exatas e naturais, se vêem agora novamente não apenas conectadas, mas outra vez submetidas àquele modelo de saber. Não se trata apenas de um neopositivismo (que também existe), mas, antes de mais nada, de uma indefinição acerca do campo daquilo que se considerava o pensamento sobre as produções culturais, calcado na interpretação, no processo de entendimento, em oposição ao modelo nomotético das demais ciências, voltado para as leis da natureza. O saber biológico e a atual revolução das neurociências apresentam um potente modelo de cultura, como um complexo sistema de hereditariedade, e do homem, como um sofisticado sistema de inscrições mnemônicas. Nosso corpo foi revelado como um arquivo. Mas não se trata mais da tripartição aristotélica da nossa alma em memória, fantasia e 
logos, nem da tripartição freudiana em id, ego e superego. Nosso corpo foi desvelado agora como um arquivo em suas bases materiais e não apenas como metáfora arquival. Com a quebra do genoma e dos procedimentos de inscrição neuronal de nossos diferentes níveis de memória, a ciência entrou em um campo que as humanidades dominavam com uma soberania que, agora vemos, era muito precária. Paralelamente a essas descobertas ocorre também a passagem para a era digital, a criação do universo da Internet, impacto que compreendemos aos poucos. Essa "nova América" também abala nossa visão de mundo: a revolução midiática, a superação dos suportes tradicionais de inscrição, apresenta o mundo, a história e o conjunto de todo saber como uma "citation à l'ordre du jour" (BENJAMIN, 1974, p. 694). Nossa cultura letrada se transforma em cultura eletrônica-digital. As fronteiras entre o eu-arquivo e o mundo-arquivo aberto pela era da computação abalam a identidade do humano.

É nesse contexto que gostaria de apresentar algumas ideias sobre a questão da memória e do arquivamento em um mundo afundado na hipermnésia do universo da web. Já tive a oportunidade de tratar em outros textos da relação entre a tradicional mnemotécnica (a "arte da memória") da Antiguidade com nosso atual panorama das artes (SELIGMANN SILVA, 2006), que mais do que nunca se entendem como uma espécie de arte da memória. Aqui enfocarei apenas alguns aspectos com relação às dificuldades da rememoração e do arquivamento. Gostaria de destacar a amnésia e a hipomnésia, como faces não menos importantes da nossa hipermnésia. Como lemos em um dos mais influentes textos dos últimos tempos sobre essa questão, o Mal de arquivo, de Derrida: "Não haveria certamente desejo de arquivo sem a finitude radical, sem a possibilidade de um esquecimento que não se limita ao recalcamento" (2001, p. 32). Esse esquecimento pode ter muitas faces: o apagamento, a tentativa de borrar da história, uma amnésia provocada por catástrofes naturais, ou ainda um esquecimento decretado, que, no fundo, como veremos, é uma contradição nos seus próprios termos.

Nossa cultura arquival e da memória é uma cultura onde grandes conflitos e guerras se articulam em torno da chave de arquivos e de certas interpretações da nossa memória cultural. Podemos ler nas guerras fundamentalistas planos de deletar da memória da humanidade as informações culturais e genéticas contidas nos grupos que são tentativamente dizimados. Tanto os genocídios, como as guerras políticas e as ditaduras, que marcaram o continente sul-americano na década de 1970, levam a graves conflitos em torno dos arquivos do terror. Em 2006, para citar um exemplo bem atual, foi anunciado que o arquivo de Bad Arolsen, na Alemanha, contendo mais de 25 quilômetros de estantes com dados sobre as vítimas da Segunda Guerra Mundial, finalmente seria aberto aos pesquisadores. Ou seja, apenas depois de mais de 60 anos de controle é que os historiadores puderam (não sem conflitos) ter acesso a essas fontes documentais primárias. No Brasil, apenas recentemente o governo federal abriu os arquivos da ditadura, mas essa abertura ainda é limitada e não é o suficiente para resolver o paradeiro dos desaparecidos pela ditadura de 1964-1985. Segundo Fábio Konder Comparato, é inconstitucional a lei que estabelece o sigilo. Ele prega a necessidade de ações individuais para o acesso a documentos, tendo em vista uma abertura maior deles ao público (http:// ctv.incubadora.fapesp.br/portal/V.artigos/arquivos, acessado em 30/05/2006). 
Como a grande pesquisadora da memória Aleida Assmann (1999) destacou, o arquivo é ao mesmo tempo uma espécie de memória recente da burocracia e um testemunho do passado. Se no termo Arkhê, como enfatizou Derrida, encontramos simultaneamente a noção de origem como de comando (2001, p. 11), é porque no arquivo se encontra aquilo que legitima o poder: tanto positiva quanto negativamente. $O$ poder depende de seus arquivos. Ele necessita, portanto, de dominar e controlar as informações aí contidas. Todo sistema de arquivo implica três movimentos básicos: a seleção, a conservação (em mais de um sentido deste termo) e o acesso às suas informações (ASSMANN, 1999, p. 344). Calcula-se que apenas 1\% dos documentos produzidos serão conservados. Mas com o tamanho virtualmente infinito do espaço da web, decerto em breve essa percentagem deve se alterar. Cada grande momento de corte histórico, nas revoluções francesa, russa, cubana e todas as demais, assim como no início e no fim dos regimes ditatoriais e na restauração da democracia, ocorrem grandes revisionismos nos arquivos. Os documentos que legitimavam o poder anterior são liberados e outros se tornam secretos. Trata-se da mesma dialética que Benjamin, em 1921, notou imperar na dinâmica entre o poder instituidor e o mantenedor do direito (SELIGMANN-SILVA, 2007), transferida para a questão dos arquivos. Assim como um (grupo de) poder substitui o outro, do mesmo modo ocorre uma revisão nos critérios de seleção daquilo que deve ser apagado, daquilo que deve ser posto no arquivo fechado e daquilo que deve ser liberado. Certas catástrofes históricas permanecem enterradas e caladas por décadas ou séculos. Esse é o caso do genocídio dos armênios, ocorrido na Primeira Guerra Mundial na Turquia, que resultou no assassinato de cerca de um milhão e meio de pessoas. Em função da continuidade da perseguição aos armênios, esse genocídio não é reconhecido até hoje, nem internamente naquele país (Turquia), nem internacionalmente; tampouco é o mesmo pesquisado. Ainda em 2005 um congresso sobre esse genocídio, que teria lugar na Universidade de Bogazici, foi impedido de ocorrer pelo governo turco (Folha de S. Paulo, 24 set.2005, A27).

As tentativas de apagamento de arquivos, por parte de regimes autoritários e totalitários, são o contraponto de um movimento apenas aparentemente paradoxal de registro, documentação e armanezamento da barbárie. Existe uma burocracia da morte que se transforma em arquivo. Em certos casos, essa auto-documentação da barbárie atingiu na história um grau de detalhamento que desafia a psicologia social. Pois se, por um lado, poderíamos argumentar que, do ponto de vista do fundamentalista, o assassinato do outro grupo é recomendável e justificável, por outro lado é sabido que em qualquer cena genocidária paira o espectro da vingança. A ideia mesma de limpeza étnica, de eliminação total do outro, visa eliminar essa possibilidade de vingança. Daí parecer paradoxal, por exemplo, a existência de dois laboratórios de fotografia dentro de Auschwitz, assim como de outros laboratórios em Buchenwald, Sachsenhausen e Mauthausen. Esses laboratórios foram destruídos antes da libertação desses campos, mas no de Auschwitz sobreviveram cerca de 39.000 retratos de identificação dos prisioneiros. No campo de Auschwitz-Birkenau, ser fotografado significava escapar da câmara de gás, ao menos nos primeiros dias (CHÉROUX, 2001, p. 54). 
Além disso, devemos pensar nas transformações nos critérios de seleção, para além daqueles que ocorrem devido à mudança nas esferas do poder, e que são, antes, determinadas por novos modelos historiográficos e memorialísticos. A virada culturalista a que me referia acima levou a uma verdadeira mudança de paradigma nesse ponto. Hoje em dia, mais e mais vale a máxima de Walter Benjamin, segundo a qual "es ist niemals ein Dokument der Kultur, ohne zugleich ein solches der Babarei zu sein" (BENJAMIN, 1974, p. 696), ou seja, "nunca existiu um documento da cultura que não fosse ao mesmo tempo um [documento] da barbárie”. É interessante ler a tradução do próprio Benjamin dessa famosa passagem das suas teses "Sobre o Conceito da História": "Tout cela [l’héritage culturel] ne témoigne [pas] de la culture sans témoigner, en même temps, de la barbárie" (BENJAMIN, 1974, p. 1263) A cultura é, a partir de meados do século XX, toda ela como que transformada em um documento e, mais ainda, ela passa a ser lida como testemunho da barbárie. Essa noção é essencial, porque com Benjamin vemos não apenas uma tremenda expansão nos critérios de seleção, como também a afirmação radical de um modo de interpretar esses documentos. Quando se fala de arquivo, não se pode esquecer que a toda inscrição deve-se associar um modo de leitura e de interpretação, de outra forma teríamos um arquivo literalmente morto. $O$ elemento político domina todos os momentos do trabalho no arquivo, da seleção, passando pela conservação e pelo acesso, chegando à leitura dos documentos. A história, para Benjamin, como é conhecido, é aproximada do modelo do colecionador e daquele do Lumpensamler, o catador de papéis. O historiador deve acumular os documentos que são como que apresentados diante do tribunal da história. Em Benjamin, a cultura como arquivo e memória, devido ao viés crítico e revolucionário de seu modo de leitura, não deixa a sociedade e sua história se cristalizarem em museus e parques temáticos. É o viés conservador da cultura como mercadoria, ao qual Benjamin opõe sua visada da cultura como documento e testemunho da barbárie, que o faz. Seu projeto de historiografia calcado no colecionismo (que tem por princípio o arrancar seus objetos do falso contexto para inseri-los dentro de uma nova ordem comandada pelos interesses de cada presente) e, por outro lado, inspirado no trabalho do catador (que se volta para o esquecido e considerado inútit) pode ser lido sobretudo no seu trabalho inconcluso sobre as passagens de Paris (BENJAMIN, 1982).

Esse trabalho, por sua vez, deve ser posto ao lado do projeto de Aby Warburg, o atlas cultural Mnemosyne, que ocupara os últimos anos da vida do famoso colecionador de livros e historiador da arte, de 1923 a 1929 (WARBURG, 2003). Nele, Warburg construiu painéis com reproduções de imagens pertencentes a diversas épocas culturais. Partindo do princípio da analogia, ele construiu constelações culturais que explodem os percursos de interpretações tradicionais da história da arte de então, vincadas por questões de estilo ou formais. Nesses dois projetos, o de Benjamin e o de Warburg, por sua vez, podemos identificar procedimentos que reaparecem na arte da memória da segunda metade do século XX, das acumulações de César aos trabalhos de Christian Boltansky, Raffael Rheinsberg e de Marina Abramovic, entre tantos outros (Cf. WEIGEL, 2005; ERMEN, 1998). 


\section{Lete: necessidade e resistência}

Benjamin reverte, portanto os valores tradicionais da seleção e da conservação. Ao invés da matéria que antes era considerada nobre e digna de ser conservada, ou seja, os documentos que recordavam as grandes ações do Estado, ele visou o lixo, os restos. Essa reversão é típica de todo projeto de desconstrução dos critérios arquivísticos que estavam na base do poder deposto. Mas pode-se pensar também a proposta benjaminiana como radicalmente crítica, ou seja, ela pode servir de base para um projeto de reestruturação dos arquivos. Não se trataria de simplesmente pôr de cabeça para baixo os critérios antigos, mas sim de implodi-los. De certo modo esse projeto tem recebido ampla acolhida na pesquisa acadêmica das últimas décadas que, dentro da virada culturalista, justamente passou a levar em conta as vozes antes não ouvidas dos oprimidos e massacrados pela máquina do expansionismo capitalista. Vivemos uma era de revisionismo histórico. A questão, como vimos, é não permitir que essa escalada da memória seja instrumentalizada pelos novos discursos da propriedade e da identidade estanque. Outro desafio é a apropriação da própria indústria cultural que mesmo na Universidade transforma esses contra-discursos em main-stream politically correct da moda, esvaziados de suas cargas políticas explosivas.

Benjamin também estava consciente dos limites desse processo de arquivamento, ou seja, dos riscos da hipermnésia. Em uma frase curta e seca de seu livro de fragmentos Rua de mão única, de 1928, ele anotou: "Uberzeugen ist unfruchtbar" (BENJAMIN, 1972, p. 87). Ou seja, desdobrando o conceito de Uberzengen, que pode funcionar como uma palavra-valise: "convencer é infecundo" ou "infrutífero", mas também, "testemunhar demais é infecundo"; ou ainda, "super-gerar é infrutífero". ${ }^{2}$ Não por acaso a avalanche de testemunhos que o século XX gerou com seu acúmulo de catástrofes provocadas pelo homem tem conduzido a reações defensivas entre os historiadores e teóricos da cultura. Para além dos positivistas, que negam qualquer valor de conhecimento aos testemunhos (e nem sequer aceitam que a história teria um teor político), mesmo entre os pensadores que tradicionalmente estão abertos para o fenômeno testemunhal constata-se hoje uma espécie de ressaca. No final de 2005, Betriz Sarlo expressou bem esse tipo de postura em seu livro de ensaios Tiempo pasado: Cultura de la memória y giro subjetivo (2005). Sua tese central é que a utopia revolucionária, com suas ideias, "recebe um tratamento injusto se a apresentamos apenas ou fundamentalmente como drama pós-moderno dos afetos" (p. 91). Essa tese é correta, mas, evidentemente, com ela não se trata de calar ou deixar de ouvir os testemunhos; antes, trata-se de buscar uma dose correta entre os discursos da memória e os da história. Um discurso não deve sufocar o outro.

Mas o dito de Benjamin que condena o Uberæengen (ou seja, ao mesmo tempo o super-gerar e o super-testemunhar) também pode ser transposto para nosso universo virtual. A questão é como selecionar. Ou ainda: como controlar a sede da web, como usar os sites de busca e como acessar - ou não - os documentos por eles listados. A web reproduz nossa estrutura mnemônica, já descrita por Aristóteles como um misto de memória e reminiscência (ARISTÓTELES, 1957). No computador temos tanto os hard-disks correspondendo à memória, como também programas de busca internos ou externos (na web) ao nosso computador. Nestas buscas recordamos, we recollect, como se fala em inglês mais 
precisamente. Mas se no computador existe a tecla deletar (que significa jogar no rio Lete) e se, ainda por cima, existem programas especializados em apagar totalmente determinados documentos de nossos computadores, o mesmo não se pode dizer com relação às informações na nossa mente. Afora os problemas físicos causados por mutilações, acidentes ou pelo envelhecimento, ainda não inventaram uma ars oblivionalis efetiva. Segundo o semiólogo Umberto Eco (1988), tal ciência seria classificada como impossível, uma vez que ela seria uma tentativa de aplicar a "arte da memória" (a mnemotécnica) de modo negativo. Mas ocorre que a arte da memória é uma semiótica, ou seja, uma arte "capaz de tornar presente algo ausente" (ECO, 1988, p. 258) Ao se presentificar o que se quer esquecer, apenas o reiteramos. Não existiria uma arte do esquecimento. Como no exemplo da famosa anedota sobre Kant, que, ao querer se esquecer de seu criado Lampe, anotou em um bilhete posteriormente encontrado em seu espólio: "Tenho de esquecer completamente o nome Lampe" (WEINRICH, 1997, p. 107). Dificilmente esse método pode ter funcionado. Assim, podemos dizer que indivíduos que sofrem de memória demais (uma das definições do traumatizado, segundo Freud) podem no máximo tentar diminuir o teor de maldade ou de tristeza de suas memórias. A terapia em certo sentido propõe isto: uma visada crítica sobre o passado que permita uma certa autonomia do sujeito com relação a ele. Ao invés de agir guiado cegamente por um passado não elaborado, o indivíduo deveria canalizar as energias do passado para uma ação libertadora no seu presente.

\section{Trauma, negacionismo e o rio da web}

Os sobreviventes de situações-limite, como campos de concentração e de torturas, tendem a desenvolver uma relação ambígua com a memória dessas experiências. Justamente pelo fato de eles não terem podido propriamente experienciar essas vivências, as imagens desse passado tendem a marcar de modo patológico a vida dessas pessoas. Elas se repetem, voltam sempre à mente, como Freud o notou, com relação às memórias de traumatizados de guerra. Esse fato também pode ser descrito em termos de psicologia social, uma vez que pode ser detectado em sociedades pós-totalitárias ou que passaram por regimes autoritários. Para além das querelas entre os grupos dos antigos detentores do poder (e responsáveis pelas barbáries cometidas) e, por outro lado, o grupo das vítimas e dos que lhes são solidários, para além desse conflito existe um dilema interno ao grupo dos sobreviventes, que sofrem dessa memória do mal. A anistia, que via de regra é decretada visando um pacto social e a reconstrução da normalidade, acaba por perpetuar a memória da dor na medida em que não permite que os processos jurídicos sanem, ao menos em parte, as injustiças e permitam um trabalho da memória do mal. $\mathrm{O}$ sobrevivente oscila entre a necessidade de narrar e a impossibilidade de esgotar com palavras suas vivências. Além disso, ele deseja com seu relato não apenas gerar memória (e, se possível, justiça), mas também gerar o seu esquecimento: como Temístocles, o general ateniense exilado na África, que gostaria de aprender de Simônides de Céos não a arte da memória, mas sim a arte do esquecimento. Essa arte, como vimos, não existe. No máximo pode-se tentar sufocar uma memória negativa sob o peso de outras memórias, 
assim como mordemos os lábios ou nos beliscamos para não sentir a dor de uma injeção. Em Atenas, recorda Nicole Loraux, as tragédias deveriam (aristotelicamente) evitar tratar dos males próximos aos que a cidade vivia para evitar a comoção descontrolada dos cidadãos. Frinico teve de pagar uma multa de mil dracmas por ter feito uma peça sobre a Tomada de Mileto, fato histórico ocorrido durante as guerras persas, que marcou muito os gregos devido à sua brutalidade (LORAUX, 1988, p. 25). ${ }^{3}$

O perverso do negacionismo (tão discutido hoje em dia por conta dos que negam a existência das câmaras de gás nazistas, mas que é típico das querelas em torno de qualquer memória do mal) está justamente em querer apagar o passado negando os fatos tremendos que as vítimas querem ao mesmo tempo narrar e esquecer. Mas esses últimos querem se esquecer porque sofrem sob a sua sombra e não para apagar as atrocidades. $\mathrm{Na}$ cena do arquivamento e do apagamento do passado (e todo arquivamento implica seleção e, portanto, esquecimento mesmo que parcial de certos aspectos desse passado) o arconte, ou seja, o detentor da chave do arquivo, o que tem o poder sobre ele, deve ser pensado como aquele também que tem as chaves da porta da justiça. A justiça não é cega, apenas talvez o seja para as injustiças que sempre e inevitavelmente comete. ${ }^{4}$ Apenas uma humanidade liberada poderia ter acesso integral à sua memória. Apenas essa sociedade estaria para além dessa estrutura jurídica que fecha também as portas da memória. $\mathrm{O}$ arconte continua do lado dos detentores do poder. Seria ilusório pensar que a web, ao menos no estágio em que se encontra agora, representa uma verdadeira democratização do arquivo. Ela pode ser utilizada nesse sentido (vide os blogs que pipocam aqui e ali sob estados autoritários, ou servem de respiro para inúmeros produtores criativos que não encontram espaço no mercado); mas ela ainda está longe de verdadeiramente abalar o poder arcôntico. Além disso, a web pode também funcionar como um Lete, o rio do esquecimento dentro da geografia mítica grega. Ela pode significar a ilusão da publicidade. O rio da web afoga a maior parte da informação a ela conectada ao invés de realmente fazê-la circular.

Mas não podemos negar que o número de informações acessíveis na ponta de nossos dedos e sob o nosso nariz, na tela brilhante do computador, aumenta vertiginosamente a cada dia. Projetos mamute de digitalização de bibliotecas estão sendo levados adiante por Amazons e Googles. Se não podemos ir às bibliotecas, elas vêm a nós. Sem contar os milhões de outros tipos de informações, jornalísticas, musicais, cinematográficas, artísticas etc., que também estão on-line. O autêntico desejo de esquecimento do sobrevivente vai agora ao encontro de nosso desejo de também não nos afogarmos dentro do crescimento exponencial de informações que nosso mundo virtual permite. Sofremos concomitantemente de hipermnésia e de amnésia. A memória demais leva também a um "apagamento" da informação por impossibilidade de metabolização da mesma. Como no Funes Memorioso de Borges (1979), nossa super-memória ameaça nos enterrar na mediocridade. Por outro lado, podemos pensar que mais vale sofrer de informação demais do que de falta e de censura da informação. Passado o pânico do bug do milênio - que, destruindo nossos arquivos, prometia nos lançar nas trevas de uma nova idade média - só nos resta esperar que o bug não se dê em nossos computadores, que a cada par de meses tem sua capacidade de memória suplantada ou, muito pior, que esse bug não ocorra diretamente dentro de nossas cabeças. Antes que isso aconteça, podemos deletar alguns 
arquivos de nossos computadores: em nossas cabeças, sem uma ars oblivionalis à vista, só nos resta recorrer à arte do esquecimento contida na própria literatura e na arte, com toda a sua carga de memória. Os Frinicos de hoje, felizmente, via de regra não são multados e devemos a eles boa parte do arquivamento vital e criativo de nossa época.

\section{Notas}

${ }^{1}$ Segundo Adorno e Horkheimer (1985), a sociedade que quer esconder sua origem no medo e na mímesis enreda-se cada vez mais em uma mímesis patológica do que provoca o pavor. O corpo rígido da sociedade, dominado pelo pavor diante de sua origem, quer preservar-se pela uniformização - e imitação de si mesma: " $\mathrm{O}$ sentido das fórmulas fascistas, da disciplina ritual, dos uniformes e de todo o aparato pretensamente irracional é possibilitar o comportamento mimético" (p. 172). Tudo o que escapa à uniformização deve ser destruído. A rebelião da natureza reprimida leva a mais repressão. Os judeus são acusados de sacrifícios sanguinários: eles mesmos devem então ser sacrificados de modo sanguinário. $\mathrm{O}$ anti-semita identifica-se com aquilo que projeta no judeu: do envenenamento do povo, à conspiração internacional para dominar o mundo. Ele transforma o mundo no inferno que ele ai antes projetou para justificar sua fúria.

${ }^{2}$ Partindo de um estudo da Oresteía de Ésquilo, analisei a relação entre uma determinada tradição do testemunho, próxima à cena da sala do tribunal, na sua relação com o "testemunho da masculinidade" (CE. SELIGMANN-SILVA, 2005).

${ }^{3}$ Loraux recorda também (1988, p. 31) da anistia de 403 a. C. em Atenas que estabeleceu uma espécie paradoxal (e impossível) de "dever de esquecimento" (me mnesikakein, "é proibido recordar-se os males"), quando do fim da violenta oligarquia dos trinta. Ela explica que se na cultura grega temos inúmeras personagens representando a memória do mal, o desejo de vingança, enfim, toda uma galeria de personagens assombradas pelas Fúrias/ Erínias e irmanadas a elas, por outro lado a política e seus decretos estavam do lado do esquecimento. A ausência de ressentimento era vista como uma grande virtude política, como lemos, entre outras obras, em De cobibenda ira de Plutarco. Plutarco elogia o fato de que no conflito entre Poseidon e Atena pelo controle de Atenas, o deus dos mares derrotado não guardou ressentimento, amenitos, para com a deusa. Os atenienses em agradecimento e essa clemência divina erigiram um altar a Lete, o esquecimento, no Erecteion. Altar ambíguo, eu acrescento, que ao homenagear o esquecimento, recorda a derrota que deveria ser esquecida. Ele na verdade comemora apenas a ausência da memória do mal, ou seja, do ressentimento. Devemos ter em conta a relação entre a noção clássica de esquecimento e a de superação do rancor (uma espécie de variante de perdão, mas que se dá em termos de uma troca ritual do esquecimento das rixas por uma coexistência pacificada). É interessante notar que ainda hoje existe uma tendência maior dos Estados no sentido de promover a reconciliação por meio do esquecimento e não tanto o reparo (jurídico ou não) dos males, como vemos no caso do Brasil pós-ditadura, mas não só. Quando processos ocorrem, como no caso da Alemanha pós terceiro Reich, eles são normalmente mais exemplares do que efetivamente restituidores de justiça. A justiça sempre fica relegada a um plano quase utópico.

${ }^{4} \mathrm{Com}$ isso não nego a necessidade do jurídico, mas apenas aponto para a necessidade de sua crítica, tal como Benjamin indicou em seu ensaio de 1921 (Cf. SELIGMANN-SILVA, 2007). O jurídico, sobretudo graças aos dispositivos do testemunho e da confissão, para além de constituir um dispositivo de equilíbrio das demandas de justiça, abre espaço para uma narrativa do mal com seus efeitos terapêuticos (Cf. FELMAN, 2002).

\section{Bibliografia}

"Rússia estuda sanções contra Estónia”. In: http://tsf.sapo.pt/PaginaInicial/Interior.aspx?content_id=821870, acessado em 30/05/2006.

http://ctv.incubadora.fapesp.br/portal/V.artigos/arquivos, acessado em 30/05/2006.

ADORNO, Theodor W., HORKHEIMER, Max. Dialética do esclarecimento: fragmentos filosóficos. Trad. Guido Almeida. Rio de Janeiro: Jorge Zahar, 1985.

ARISTÓTELES. On memory and recollection. In: - On the Soul, Parva Naturalia, On Breath. Trad. W.S. Hett. Cambridge (Mass.) /London: Harvard UP, 1957. p. 285-313. 
ASSMANN, Aleida. Erinnerungsräume: Formen und Wandlungen des kulturellen Gedächtnisses. Munchen: C.H. Beck, 1999.

BENJAMIN, Walter. Gesammelte Schriften. Org. por R. Tiedemann, H. Schweppenhäuser. Frankfurt a.M.: Suhrkamp, vol. IV: Kleine Prosa. Baudelaire-Ubertragungen, 1972.

BENJAMIN, Walter. Gesammelte Schriften. Org. por R. Tiedemann, H. Schweppenhäuser. Frankfurt a.M.: Suhrkamp, vol. I: Abhandlungen, 1974.

BENJAMIN, Walter. Gesammelte Schriften. Org. por R. Tiedemann, H. Schweppenhäuser. Frankfurt a.M.: Suhrkamp, vol. V: Das Passagen-Werk, 1982.

BENJAMIN, Walter. Gesammelte Schriften, org. por R. Tiedemann e H. Schweppenhäuser, Frankfurt a.M.: Suhrkamp, volume VII, 1989.

BORGES, Jorge Luis. Prosa completa. Barcelona: Bruguera, 1979, vol. 1, pp. 477-484.

CHEROUX, Clément (Org.). Mémoire des Camps: Photographies des Camps de Concentration et d'Extermination nazis (1933-1999). Paris: Marval, 2001.

DERRIDA, Jacques. Mal de arquivo: uma impressão freudiana. Trad. C. de Moraes Rego. Rio de Janeiro: Relume Dumará, 2001.

ECO, Umberto. An ars oblivionalis? Forget it!. PMLA. Londres, 103, n. 3, p. 254-261, 1988.

ERMEN, Reinhard, RHEINSBERG, Raffael. Ich such nichts, sondern ich finde. Kunstforum, vol. 140 (Kunst und Literatur II), p. 295-309, abril-junho 1998.

FELMAN, Shoshana. The Juridical Unconscious: Trials and Traumas in the Twentieth Century. Cambridge: Harvard UP, 2002.

FLUSSER, Vilém. Bodenlos: uma autobiografia filosófica. São Paulo: AnnaBlueme, 2007.

LORAUX, Nicole. De l'amnistie et de son contraire. In: Usages de l'oubli. Paris : Seuil, 1988.

SARLO, Beatriz. Tiempo pasado: cultura de la memoria y giro subjetivo. Buenos Aires: Siglo XXI Editores, 2005.

SELIGMANN-SILVA, Márcio. A escritura da memória: mostrar palavras e narrar imagens. Remate de Males, Revista do Departamento de Teoria Literária do IEL, UNICAMP, n. 26, v. 1 (Dossiê Literatura como uma arte da memória), p. 31-45, janeiro-junho, 2006.

SELIGMANN-SILVA, Márcio. Testemunho e a política da memória: o tempo depois das catástrofes. Projeto História, Revista do Programa de Estudos Pós-Graduados em História e do Departamento de História da PUC-SP, n. 30 (Guerra, Império e Revolução), p. 31-78, jun. 2005.

SELIGMANN-SILVA, Márcio. Walter Benjamin: o estado de exceção entre o político e o estético. In: SELIGMANN-SILVA, Márcio (org.). Leituras de Walter Benjamin, São Paulo: Annablume/FAPESP, segunda edição, revista e ampliada, 2007. Pp.: 213-238.

WARBURG, Aby. Der Bilderatlas Mnemosyne. Editado por Martin Warnke. Berlin: Akademie Verlag, 2003. (Gesammelte Schriften, segunda seção, vol II. 1)

WEIGEL, Siegrid. Die Kusnt des Gedächtnisses - das Gedächtnis der Kunst. Zwischen Archiv und Bilderatlas, zwischen Alphabetisierung und Spur. In: FLACH, Sabine, MUNZ-KOENEN, Inge, STREISAND, Marianne (Org.). Der Bilderatlas im Wechsel der Kunste und Medien. Munchen: Wilhelm Fink Verlag, 2005. p. 99-119.

WEINRICH, Harald. Lethe - Kunst und Kritik des Vergessens. Munchen: C.H. Beck, 1997. 
